\title{
PANKREAS KANSERINDE PROGROSTIK FAKTÖRLER
}

\section{PROGNOSTIC FACTORS IN PANCREATIC CANCER}

\author{
Şirin ÇETiN ${ }^{1}$, İsa DEDE ${ }^{2}$ \\ ${ }^{1}$ Ondokuz Mayıs Üniversitesi, Samsun, \\ 2 Antakya Devlet Hastanesi, Tibbi Onkoloji Kliniği \\ Cite this article as: Çetin Ş, Dede I. Prognostic Factors in Pancreatic Cancer.Med J SDU 2019; 26(1): 30-34.
}

Öz

\section{Giriş}

Bu çalışmada amaç pankreas kanseri tanısı alan olguların klinik özelliklerinin ve risk faktörleri ile ilişkisinin retrospektif olarak değerlendirilmesi ve pankreatik kanserli hastaların yaşam süresini etkileyen prognostik faktörlerin araştırılmasıdır.

\section{Materyal ve Metot}

Çalışmada pankreas tanısı almış 144 hastanın demografik ve klinik özellikleri incelendi. Demografik ve klinik özelliklerin sağkalım ile ilişkisini incelemek için istatistiksel analizler yapıldı. Sağkalım eğrilerinin çiziminde Kaplan-Meier metodu kullanıldı. Prognostik faktörlerin sağkalım analizleri log-rank testi kullanılarak hesaplandı.

\section{Bulgular}

Pankreatik kanserli 144 hastanın ortanca sağkalım süresi 11 ay (\%95 Cl 8.92-13.07) olarak bulundu. Cox regresyon analizi sonucunda yaş, diyabet, kilo kaybı ve alkol kullanımının pankreatik kanserli hastalarda sağkalımla ilişkilerinin anlamlı olduğu saptandı $p<0.005)$.

\section{Sonuç}

Çalışmamızda pankreas kanserli hastaların sağkalım süresini etkileyen prognostik faktörlerin etkisi değerlendirilmiştir.

Anahtar Kelimeler: Pankreas kanseri, prognostik faktörler,demografik özellikler

\section{Abstract}

\section{Introduction}

This study aims to determine the clinical features of cases with pancreatic cancer as well as their association with risk factors and investigate prognostic factors affecting survival retrospectively.

\section{Materials and Methods}

Demographic and clinical features of 144 patients with pancreatic cancer were evaluated. Statistical analysis was performed to identify the relation between such features and survival. Survival rates were obtained using Kaplan-Meier estimator using.

\section{Results}

Median overall survival of 144 patients with pancreatic cancer were estimated to be 11 months $(95 \% \mathrm{Cl}$ 8.92-13.07). Cox regression analysis revealed that age, presence of diabetes, weight loss and consuming alcohol were significantly associated with survival in patients with pancreatic cancer.

\section{Discussion}

This study evaluated the impact of prognostic factors that influence survival rate of patients with pancreatic cancer.

Keywords: Pancreatic cancer, prognostic factors, demographic features.

İletişim kurulacak yazar/Corresponding author: cetinsirin55@gmail.com Müracaat tarihi/Application Date: 16.05.2018 • Kabul tarihi/Accepted Date: 20.09.2018 CCopyright 2018 by Med J SDU - Available online at http://dergipark.gov.tr/sdutfd CTelif Hakkı 2018 SDÜ Tıp Fak Derg - Makaleye http://dergipark.gov.tr/sdutfd web sayfasından ulaşılabilir. 


\section{Giriş}

Pankreas kanseri dünyada kansere bağlı mortalitede dördüncü ve en yaygın kanserler sıralamasında beşinci sırada yer almaktadır (1). Pankreas kanseri gastrointestinal kanserler arasında son yıllarda giderek artan sıklığı ile dikkat çekmekte ve gastrointestinal kanser ile ilişkili ölümlerde ülkemizde mide ve kolon kanserinden sonra gelmektedir (2). Pankreas kanseri 1 yıllık genel sağkalım oranı \%26 ve 5 yıllık sağkalım oranı \%5'ten daha az olan son derece malign solid bir tümördür. Tanı ve tedavide büyük çabalar gösterilmesine rağmen, hastalığın prognozu kötüdür. Tanı anında genellikle hastalığın ileri evresi ve uzak organ metastazı ile karşılaşılır. Burada en önemli etken, hastalığın erken evresinde belirgin spesifik semptomların olmayışıdır. Hastaların büyük çoğunluğu tanı anında küratif rezeksiyon şansını kaybetmiştir (3) Hastaların yalnız \% 20'si cerrahi rezeksiyon şansına sahiptir (4) Pankreas kanserinde hastaya bağlı pek çok faktörün sağkalımı etkilediği bildirilmiştir. Tümörün boyutu, lokasyonu, graydi, lenf nodu ilişkisi klinik sonuçlar ile ilişkilendirilmiştir (5). Pankreas kanseri insidansı ve ölüm oranı, ilerleyen yaşla birlikte artmaktadır (6). Pankreas kanseri ileri yaşlarda görülmekle birlikte, nadiren 45 yaş öncesi rastlanır ve 50 yaş üstünde görülme oranı çok yüksektir. Erkeklerde daha sık rastlanmakla birlikte siyah ırkta daha fazla görülmektedir. Afrika ve Amerikalılarda yıllık insidans oranı 15.3/100.000 iken, beyaz populasyonda bu oran 11.6/100000'e gerilemiştir (7).

Kalıtsal etiyolojiler pankreas kanserlerinde \%10'dan daha az olsa bile kalıtsal pankreatit en önemli etkenlerden birisidir. Kronik pankreatitin kalıtsal olmayan formları pankreas kanseri geliştirme olaslığına sahiptir. Sigara ve alkol kullanımı kronik pankreatitte tümör gelişimini etkileyebilir (8).

Pankreas kanserinde çevresel faktörler arasında beslenmenin daha az etkisi olabileceği bildirilmiştir. Bazı çalışmalarda fazla miktarda kırmızı et veya işlenmiş et tüketiminin kanser gelişiminde risk oluşturabileceği ileri sürülmüştür (9).

Pankreas kanserinde Diabetes mellitus'un risk faktörü olabileceği bildirilmiştir (10). Yapılan araştırmalar sonucu Diyabet hastalığı, siroz ve kolesistektomi öyküsü, artan kanser riskiyle ilişkili bulunmuştur (11). Düşük düzeyde fiziksel aktivitenin, pankreas kanser riskini artırdığı ifade edilmektedir (12).

Bu çalışmanın amacı pankreatik kanserli hastaların yaşam süresini etkileyen prognostik faktörleri araştırmaktır.

\section{Gereç Yöntem}

Ocak 2014 ve Aralık 2017 yılları arasında Antakya Devlet Hastanesi Medikal Onkoloji Kiniğine kabul edilen pankreas kanseri tanısı almış olan 144 hasta çalışmaya alındı. Bu çalışmada hastaların ECOG performans skorları da değerlendirilmiştir. Değerlendirmede ECOG (Eastern Cooperative Onkology Group) performans skalasına göre belirlenmiştir. Retrospektif olarak hasta dosyaları taranarak tüm hastaların yaş, cinsiyet, tanı tarihi, kilo kaybı, alkol, sigara,diyabet öyküsü, metastaz yerleri ve sayısı, ECOG Performans skalasına göre değerlendirilmiş performans durumları, ölüm tarihleri, hayatta olanlar için en son poliklinik kontrol tarihleri tespit edilmiştir.

İstatistiksel analizler için SPSS (version 21; IBM, Armonk, NY) paket programı kullanıldı. Prognostik faktörlerin sağkalım üzerindeki etkilerini araştırmak için Log-rank testi ve sağkalım eğrilerinin çiziminde Kaplan-Meier metodu uygulanmıştır.

\section{Bulgular}

Genel sağkalım, tanı başlangıcından ölüm ya da son değerlendirmeye kadar geçen süre olarak tanımlandı. Çalışmaya alınan 144 hastanın 95 (\%62.10) erkek, 49 (\%32.0) kadındı. Hastaların tanı anındaki yaşı 40-91 arasında değişmekte olup ortalama yaş 66.78 \pm 9.59 idi. Erkeklerin yaş ortalaması 66.46 kadınların yaş ortalaması ise 67.40 olarak saptandı. Hastaların takip süresi sonunda 98 (\%68.10)'inin exitus olduğu gözlendi. ex olduğu gözlendi. Bu çalışmada hastaların ortanca sağkalım süresi 11 ay $\% 95 \mathrm{Cl}$ 8.9213.07) olarak bulundu. Çalışmaya alınan 144 hastada tanı anında 32 (\%22.20)sinde metastaz yokken 112 (\%77.80)'inde metastaz vardı. Metastaz bölgeleri incelendiğinde; 65 (\%45.10 )hastanın bir bölgesinde metastaz, 32 (\%22.20) hastanın iki bölgesinde metastaz, 13 (\%9) hastanın üç bölgesinde metastaz ve 2 (\%1.40) hastanın dört bölgesinde metastaz bulunmaktaydı.

144 hastanın 51 (\%35.4)'ında ECOG performans skoru 0, 78(\%54.2)ında ECOG performans skoru 1, 12(\%8.3)inde ECOG performans skoru 2, $2(\% 1,4)$ inde ECOG performans skoru 3, 1(\%0,7)inde ECOG performans skoru 4 dü.

Çalışmamızdaki 144 hastanın 70(\%48.60)'ında diyabet yokken, 74(\%51.40) hastada diyabet vardı. Sağ kalımın tek değişkenli analizlerle incelenmesi log rank testi ile yapıldı (Tablo1). 
Analize alınan 144 hastanın ortanca sağkalım süresi 11 ay (\%95 Cl 8.92-13.07) olarak bulundu (Şekil 1). Erkek hastaların sağkalım süresi 10 ay $(\% 95 \mathrm{Cl}$ 3.60- 16.39) idi (Tablo 1). Kadın hastaların sağkalım süresi 11 ay (\%95 Cl 8.90-13.09) olarak bulunurken cinsiyetler ile sağkalım arasında anlamlı istatistiksel fark bulunamadı $(p=0.700)$. 65 yaș altı pankreatik kanserli hastaların sağkalım süresi 15.00 ay (\%95 Cl 10.72- 19.27) olarak bulundu. (Tablo 1). 65 yaş ve üzeri büyük pankreatik kanserli hastaların sağkalım süresi 8.00 ay (\%95 Cl 4.58-11.41) olarak bulunurken yaş ile sağkalım arasında istatistiksel anlamlı fark bulundu $(p=0.013)$. Diyabet hastası olmayan hastaların sağkalım süresi 13 ay (\%95 Cl 8.41-17.58) olarak bulundu. Diyabet hastası olan hastaların sağkalım süresi 9 ay $(\% 95 \mathrm{Cl} 5.82-12.17)$ olarak bulunurken diyabet hastalığı ile sağkalım arasında önemli fark bulundu $(p=0.005)$. Kilo kaybı olmayan pankreatik kanserli hastalarda sağkalım süresi 15 ay $(\% 95 \mathrm{Cl}$ 10.17-19.82) bulundu. Kilo kaybı olan pankreatik kanserli hastalarda sağkalım süresi ise 8 ay $(\% 95 \mathrm{Cl} 4.93$ -11.06) bulunurken kilo kaybı ile sağkalım arasında istatistiki olarak önemli fark bulundu $(p=0.001)$. Alkol kullanmayan pankreatik kanserli hastalarda sağkalım süresi 15 ay (\%95 Cl 6.72-23.27) bulundu. Alkol kul- lanan pankreatik kanserli hastalarda sağkalım süresi 6 ay (\%95 $\mathrm{Cl}$ 3.15-8.84) bulunurken alkol kullanma ile sağkalım arasında istatistiki olarak önemli fark bulundu $(p<0.001)$. Sigara kullanmayan pankreatik kanserli hastalarda sağkalım süresi 12 ay $(\% 95 \mathrm{Cl}$ 7.88- 16.11) bulunmuştur. Sigara kullanan pankreatik kanserli hastalarda sağkalım süresi 9 ay $(\% 95 \mathrm{Cl}$

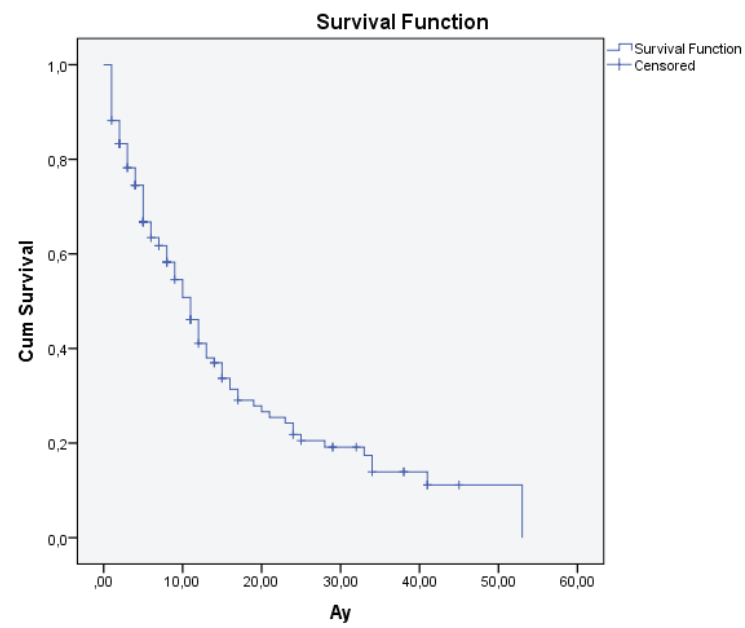

Şekil 1. Tüm hastalara ilişkin genel sağkalım eğrisi

\begin{tabular}{|c|c|c|c|}
\hline & Hasta Sayısı & $\begin{array}{l}\text { Ortanca Sağkalım Ay } \\
\text { (\%95 Güven Aralığı) }\end{array}$ & $p$ \\
\hline $\begin{array}{l}\text { Cinsiyet } \\
\text { Kadın } \\
\text { Erkek }\end{array}$ & $\begin{array}{l}49 \\
95\end{array}$ & $\begin{array}{l}11(8.90-13.09) \\
10(3.60-16.39)\end{array}$ & 0.700 \\
\hline $\begin{array}{l}\text { Yaş } \\
<65 \\
\geq 65\end{array}$ & $\begin{array}{l}56 \\
88\end{array}$ & $\begin{array}{c}15(10.72-19.27) \\
8(4.58-11.41)\end{array}$ & 0.013 \\
\hline $\begin{array}{l}\text { Diyabet öyküsü } \\
\text { Yok } \\
\text { Var }\end{array}$ & $\begin{array}{l}70 \\
74\end{array}$ & $\begin{array}{c}13(8.41-17.58) \\
9(5.82-12.17)\end{array}$ & 0.005 \\
\hline $\begin{array}{l}\text { Kilo kaybı } \\
\text { Yok } \\
\text { Var }\end{array}$ & $\begin{array}{l}67 \\
77\end{array}$ & $\begin{array}{l}15(10.17-19.82) \\
8(4.93-11.06)\end{array}$ & 0.001 \\
\hline $\begin{array}{l}\text { Alkol } \\
\text { Yok } \\
\text { Var }\end{array}$ & $\begin{array}{l}84 \\
60\end{array}$ & $\begin{array}{r}15(\% 95 \mathrm{Cl} 6.72-23.27) \\
6(\% 95 \mathrm{Cl} 3.15-8.84)\end{array}$ & $<0.001$ \\
\hline $\begin{array}{l}\text { Sigara } \\
\text { Yok } \\
\text { Var }\end{array}$ & $\begin{array}{l}88 \\
56\end{array}$ & $\begin{array}{c}12(\% 95 \mathrm{Cl} 7.88-16.11) \\
9(\% 95 \mathrm{Cl} 5.50-12.49)\end{array}$ & 0.052 \\
\hline $\begin{array}{l}\text { ECOG PS } \\
0-2 \\
2>\end{array}$ & $\begin{array}{c}129 \\
15\end{array}$ & $\begin{array}{l}16(\% 95 \text { Cl } 7.20-24.79) \\
10(\% 95 \text { Cl } 7.61-12.38)\end{array}$ & 0.323 \\
\hline
\end{tabular}


5.50-12.49) bulunurken sigara kullanma ile sağkaIım arasında istatistiki olarak anlamlı fark bulunmadı $(p=0.052)$. ECOG performans skoru 0 ile 2 arasında olan hastaların sağkalım süresi 16 ay $(\% 95 \mathrm{Cl} 7.20-$ 24.79) bulundu. ECOG performans skoru 2 den büyük olan hastaların sağkalım süresi 10 ay $(\% 95 \mathrm{Cl}$ 7.61-12.38) olarak bulunurken ECOG performans skoru ile sağkalım arasında istatistiksel olarak anlamlı fark bulunmadı $(\mathrm{p}=0.323)$.

Yaş<65 olan pankreatik kanserli hastaların sağkalım süresi 15.00 ay (\%95 Cl 10.72- 19.27) ve yaş $\geq 65$ olan pankreatik kanserli hastaların sağkalım süresi 8.00 ay (\%95 Cl 4.58-11.41) olarak bulundu (Şekil 2).

Diyabet hastası olmayan hastaların sağkalım süresi 13 ay (\%95 Cl 8.41-17.58) iken Diyabet hastası olan

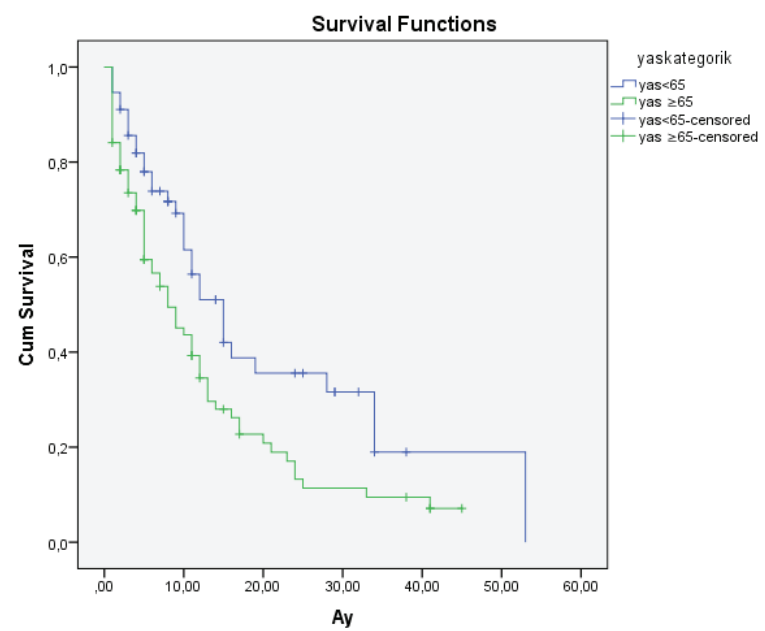

Şekil 2. .Yaşa göre sağkalım eğrisi

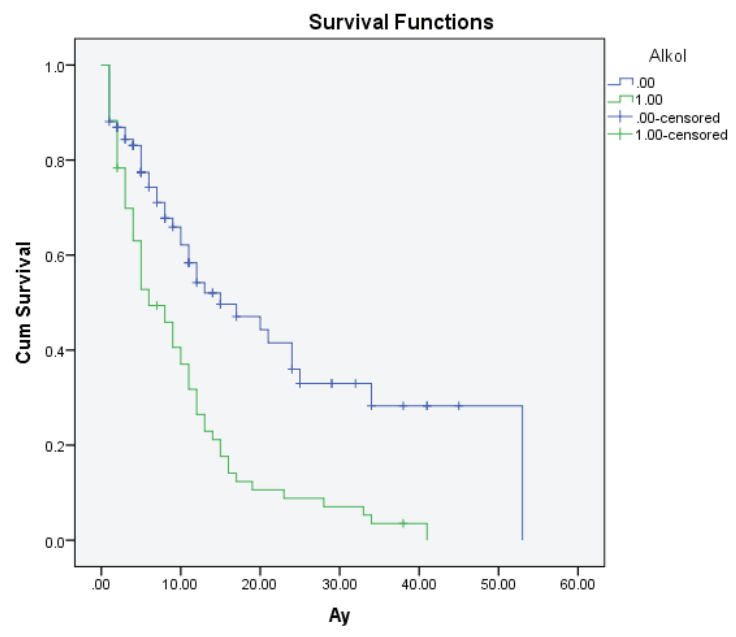

Şekil 4. Alkol kullanımına göre sağkalım eğrisi hastaların sağkalım süresi 9 ay (\%95 CI 5.82-12.17) olarak bulundu (Şekil 3).

Alkol kullanan pankreatik kanserli hastalarda sağkaIım süresi 6 ay (\%95 Cl 3.15-8.84) bulunurken Alkol kullanmayan pankreatik kanserli hastalarda sağkalım süresi 15 ay (\%95 Cl 6.72-23.27) bulunmuştur (Şekil 4). Alkol kullanımının genel sağkalım üzerindeki etkisi olarak anlamlı bulundu $(p<0.001)$.

Kilo kaybı olan pankreatik kanserli hastalarda sağkalım süresi ise 8 ay (\%95 Cl 4.93 -11.06) iken; Kilo kaybı olmayan pankreatik kanserli hastalarda sağkaIım süresi 15 ay (\%95 Cl 10.17-19.82) olarak bulundu (Şekil 5). Kilo kaybının genel sağkalım üzerindeki etkisi istatistiki olarak anlamlı bulundu $(\mathrm{p}=0.001)$.

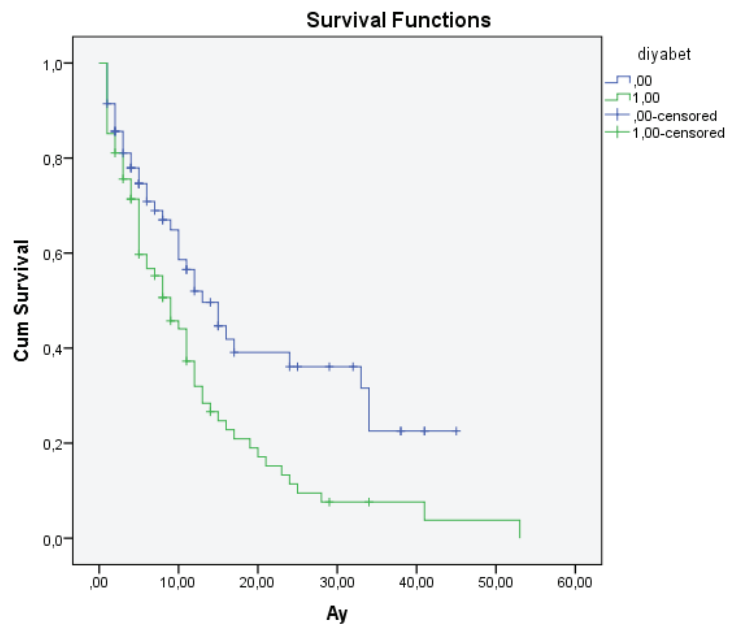

Şekil 3. Diyabet durumuna göre sağkalım eğrisi

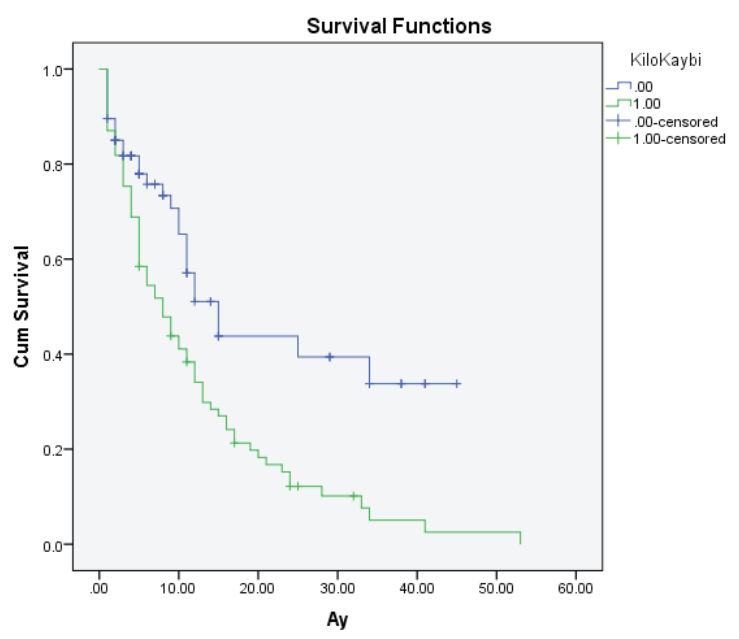

Şekil 5. Kilo kaybına göre sağkalım eğrisi 


\section{Tartışma}

Cox regresyon analizi sonucunda yaş, diyabet, kilo kaybı ve alkol kullanımının pankreatik kanserli hastalarda sağkalımla ilişkili olduğu saptanmıştır. Gao ve ark. 122 pankreas kanseri hastasının 25 aylık takibi sonucu ortanca sağkalım süresini 10 ay (9.73-10.27 ay) olarak bildirmiştir (13). Çalışmamızda 144 pankreatik kanserli hastanın ortanca sağkalım süresi 11 ay (\%95 Cl 8.92-13.07) olarak bulunmuştur. Peixoto ve ark. pankreas kanserli hastalarda ortanca sağkalım süresini 11.7 ay bulmuşlardır (14).

Çalışmamızda hastalarımızın alkol tüketimi incelendiğinde; 60(\%41.66) hastanın alkol öyküsü bulunurken, 84 (\%58.33) hastanın alkol öyküsü yoktu. Alkol kullanan pankreatik kanserli hastalarda sağkalım süresi 6 ay (\%95 Cl 3.15-8.84) bulunurken alkol kullanmayan pankreatik kanserli hastalarda sağkalım süresi 15 ay (\%95 Cl 6.72-23.27) bulunmuştur. Yapılan çalışmalarda alkol tüketiminin pankreas kanseri için önemli bir risk faktörü olduğu bildirilmiştir (15) Pankreas kanseri ile diyabet arasındaki ilişki literatürde tam olarak açığa kavuşmamıştır. Diyabet pankreas kanserinin klinik bir belirtisi olarak ortaya çıkabileceği gibi, diyabet de pankreas kanseri gelişimi için bir risk faktörü olarak kabul edilebilir. Yapılan bir çalışmada diyabet tanısı konmuş hastaların pankreas kanseri olma riskinin olmayanlara göre 2 kat daha fazla olduğu bildirilmiş̧ir (16). Bizim çalışmamızda Diyabet hastası olmayan hastaların sağkalım süresi 13 ay $(\% 95 \mathrm{Cl}$ 8.41-17.58) bulunurken Diyabet hastası olan hastaların sağkalım süresi 9 ay (\%95 Cl 5.82-12.17) olarak bulundu. Yapılan bir çalışmada, diyabet ve aşırı alkol tüketiminin önemli oranda pankreas kanserini riskini arttırdığı bulunmuştur (17) Sarılık, ağı, iştahsızlık ve kilo kaybı pankreas kanserli hastalarda en sık görülen semptomlar olduğu bilinmektedir. Çalışmamızda kilo kaybı olan pankreatik kanserli hastalarda sağkalım süresi ise 8 ay (\%95 Cl 4.93 -11.06) iken; kilo kaybı olmayan pankreatik kanserli hastalarda sağkalım süresi 15 ay (\%95 Cl 10.17-19.82) olarak bulundu. Kilo kaybı ile sağkalım arasındaki fark önemli bulunmuştur $(p=0.001)$. Yapılan bir çalışmada 40 yaş ve üzerinde pankreas kanseri görülme riski her on yılda bir yaklaşık 3 kat arttığı bildirilmiştir (18).

Çalışmamızdaki hastaların sonuçları genel olarak literatür sonuçlarıyla uyumlu olarak bulunmuştur. Pankreas kanseri, insidansı giderek artan, etyolojisi tam olarak açığa çıkarılamamışıı.

Çıkar Çatışması Beyanı: Yazarlar çıkar çatışması olmadığını bildirmişlerdir.
Finansal Destek: Bu çalışma her hangi bir fon tarafından desteklenmemiştir.

Declaration of Conflicting Interests: The authors declare that they have no conflict of interest. Financial Disclosure: No financial support was received.

\section{Kaynaklar}

1. Warshaw, A. L. \& Castillo, C. F.-d. Pancreatic carcinoma. New England Journal of Medicine 1992; 326: 455-465.

2. Ozkan $\mathrm{H}$, Ozturk $\mathrm{H}$. Pankreas kanserinde epidemiyoloji ve risk faktorleri. MN-Klinik Bilimler 2000; 6(1):39-43.

3. Howlader N, Noone A, Kracho M, et al. SEER Cancer Statistics Review 1975-2009 (Vintage 2009 Populations). Bethesta, MD. National Cancer Institute, 2012.

4. Halfdanarson TR, Rabe KG, Rubin J and Petersen GM: Pancreatic neuroendocrine tumors (PNETs): Incidence, prognosis and recent trend toward improved survival. Ann Oncol 19: 1727 1733, 2008

5. Fortner JG, Klimstra DS, Senie RT, et al. Tumor size is the primary prognosticator for pancreatic cancer after regional pancreatectomy. Ann Surg. 1996;223:147-153.

6. Muniraj T, Jamidar PA, Aslanian HR, 2013. Pancreatic cancer: a comprehensive review and update. Dis Mon, 59, 368-402.

7. Cancer Facts and Figures 2013. Atlanta: American Cancer Society; 2013.

8. Yadav D, Lowenfels A. The epidemiology of pancreatitis and pancreatic cancer. Gastroenterology 2013; 144:1252-61.

9. Larsson SC, Wolk A, Red and processed meat consumption and risk of pancreatic cancer: meta-analysis of prospective studies, Br J Cancer. 2012 ;106(3):603-607)

10. Chari S, Leibson C, Rabe K, et al. Pancreatic cancancer-associated diabetes mellitus: Prevalence and temporal association with diagnosis of cancer. Gastroenterology 2008; 134:95-101.

11. Lowenfels $A B$, Maisonneuve P. Epidemiology and risk factors for pancreatic cancer. Best Pract Res Clin Gastroenterol 2006; 20: 197-209.

12. Ryan DP, Grossbard ML. Pancreatic cancer: local success and distant failure. Oncologist 1998; 3: 178-188.

13. Gao Y, Wang WJ, Zhi Q, Shen M, Jiang M, Bian X, Gong FR, Zhou C, Lian L, Wu MY, Feng J, Tao M, Li W. Neutrophil/lymphocyte ratio is a more sensitive systemic inflammatory response biomarker than platelet/lymphocyte ratio in the prognosis evaluation of unresectable pancreatic cancer. Oncotarget. 2017 Sep 27;8(51):88835-88844

14. Peixoto RD, Speers C, McGahan CE, Renouf DJ, Schaeffer DF, Kennecke HF. Prognostic factors and sites of metastasis in unresectable locally advanced pancreatic cancer. Cancer Med. 2015 Aug;4(8):1171-7.

15. Go VLW, Gukovskaya A, Pandol SJ, Alcohol and pancreatic cancer. 2005;35(3):205-211

16. Gullo L, Pezzilli R, Morselli-Labate AM. Diabetes and the risk of pancreatic cancer. N Engl J Med, 1994; 331: 81-84

17. Hassan MM, Bondy ML, Wolff RA, et al. Risk factors for pancreatic cancer. American Journal of Gastroenterology. 2007;102(12):2696-2707

18. AbeloffMD, Armitage JO, Niederhuber JE, Carcinoma of the Pancreas. Clinical Oncology. 4 thed. Philadelphia 2008.p. 1596 